The University of San Francisco

USF Scholarship: a digital repository @ Gleeson Library | Geschke Center

Nursing and Health Professions Faculty Research and Publications

School of Nursing and Health Professions

2015

\title{
Critical Cultural Awareness and Diversity in Nursing: A Minority Perspective
}

Chenit Ong-Flaherty

University of San Francisco, congflaherty@usfca.edu

Follow this and additional works at: http://repository.usfca.edu/nursing_fac

Part of the Nursing Commons

\section{Recommended Citation}

Chenit Ong-Flaherty, Critical Cultural Awareness and Diversity in Nursing: A Minority Perspective, Nurse Leader, Volume 13, Issue 5, October 2015, Pages 58-62, ISSN 1541-4612, http://dx.doi.org/10.1016/j.mnl.2015.03.012.

This Article is brought to you for free and open access by the School of Nursing and Health Professions at USF Scholarship: a digital repository @ Gleeson Library | Geschke Center. It has been accepted for inclusion in Nursing and Health Professions Faculty Research and Publications by an authorized administrator of USF Scholarship: a digital repository @ Gleeson Library | Geschke Center. For more information, please contact repository@usfca.edu. 


\section{Critical Cultural Awareness and Diversity in Nursing: A Minority Perspective}

Author: Chenit Ong-Flaherty ${ }^{\mathrm{a}}$, RN, DNP

aUniversity of San Francisco, School of Nursing and Health Profession, 2130 Fulton Street, San Francisco, CA 94117. Email: congflaherty@usfca.edu

(C) 2015. This manuscript version is made available under the CC-BY-NC-ND 4.0

license http://creativecommons.org/licenses/by-nc-nd/4.0/ 


\title{
Critical Cultural Awareness and Diversity in Nursing: A Minority Perspective
}

\begin{abstract}
Increasing multiculturalism and ongoing issues related to poor patient-centered care, teamwork, and safety call for urgent readdressing of cultural competency training. Critical cultural awareness education is needed to improve diversity in the nursing profession. Using Hofstede's cultural dimension of InvidualismCollectivism, this paper proposes that the dominance of one culture may be the contributory factor in the slow acceptance of change towards critical cultural awareness education. Experiential learning by way of gaming and critical reflection on cross-cultural interactions can contribute to the development of critical cultural awareness.
\end{abstract}

\section{Keywords}

Critical cultural awareness, patient-centered care, individualism-collectivism, diversity, gaming. 


\section{Introduction}

With globalization and migration, the significance of culture in our daily lives has become more acute. Cross-cultural interactions have grown exponentially - from multinational corporations to aviation, people from different cultures interact, some interactions more successful than others. These interactions present with outcomes to match be it in the form of an efficient and successful business or a sentinel event of an aviation accident. A quick survey of any hospital in the San Francisco Bay Area alone will find great diversity, with more than 110 languages spoken ${ }^{[1]}$. The increase in multicultural interactions in healthcare has made care provision more complicated. There has been much attention given to organizational culture, team development, and effective communication. Similarly, there is the call for patient-centered care, which must incorporate cultural needs and respect for patient wishes, and that providers must work on becoming "culturally competent". Indeed, there is much attention given to the importance of culture. Yet, too frequently, one still encounters the reality of cultural ethnocentrism. It is disturbing when ethnocentrism rears its ugly head in healthcare.

After more than two decades of educating healthcare providers on cultural competency, it begets the question why culturally insensitive care and care disparities, as well as the protracted struggle for better communication and teamwork in healthcare, still persist. The first problem lies in the outdated application of "cultural competency" based on the didactic approach to teaching ethnic-based information without developing critical understanding and appreciation of cultural dimensions. The second, and possibly the more important factor, may lie in the profession itself. Nursing comprises largely of White women; the schema of thought of a dominant culture has significant implications on how culture is addressed ${ }^{[2]}$. Critical cultural awareness and diversity go hand-in-hand; solutions for each must include the other.

Cross-cultural training must be readdressed, moving away from limiting ethnic-based information to a comprehensive program entailing experiential and reflective learning. It should incorporate cultural concepts or dimensions such as individualism versus collectivism and power distance, integrating the lived experience of people from historical and sociological contexts. This training should start with nursing leaders, and for that matter, all leaders in healthcare. For this to happen it will take great leadership; this change calls for ethical leadership with foresight, courage, and the ability to see outside the "norm" that understands the importance of diversity in closing the provider-patient gap ${ }^{[2,3]}$. Addressing critical cultural awareness may encourage minorities to be more inclined to join the profession both as clinicians and educators.

\section{The Cultural Dimension of Collectivism versus Individualism}

The social psychologist, Geert Hofstede, began his work in the 1960's on the premise that individuals are influenced by the culture in which we are nurtured. Culture is defined as the norm or the schema of thought that we are programed in, or as Hofstede calls it, the "software of the mind" ${ }^{[4]}$. In childhood, the culture in which we are nurtured influences our perspectives, morals, beliefs, thoughts, and behaviors. At professional school, we are programed by professional expectations. At work, organizational culture adds another layer of complexity to the cultural stage on which we act. The norm is an expectation that is not challenged until cross-cultural interaction occurs. Understanding other cultures does not automatically occur. It takes guidance and the ability to critically reflect that individuals can move away from judgment and to be open to new ideas and realities. Ultimately, a person can develop cultural awareness to the level where a culture can be switched on and off depending the environment and situation, a level of sophistication analogous to emotional intelligence ${ }^{[4,5,6]}$.

Hofstede's survey of hundreds of thousands of people all over the world brought him to develop cultural dimensions. His original four are: individualism-collectivism — addressed in this paper; power distance; masculinity-femininity; and uncertainty avoidance. His earliest works have been replicated for validity and reliability, widely cited, and adopted by multinational corporations and various industries, including the critical work by Robert Helmreich who co-created the Cockpit Resource Management (CRM) for aeronautical and aviation safety ${ }^{[4,5,6,7,8,8,9,10]}$. 
The dimension of collectivism/individualism may have the most significant influence on perspectives and behaviors ${ }^{[3,5,10,11,12]}$. The dichotomy of "us versus them" is accentuated by the very different worldviews of "self" in collectivism and individualism. In the collectivist mind, the "self" is connected to a group. This connection to others is imperative in how the "self" functions. Actions reflect not just one individual but everyone connected to that individual. Priorities lie in maintaining the good standing of the group; harmony is emphasized as with the understanding not to shame anyone. Successes are celebrated as group successes. Communication is high-context, indirect with subtleties in meaning for the purpose of maintaining harmonious relationships. Goals are similarly group-oriented

On the opposite end is individualism. As the word implies, the "self" in individualism is about the autonomous individual, separate from everyone else. "I" and "me" matters most as in the principles of individual rights and autonomy. Actions reflect just one individual as with consequences of actions-how does an action affect "me"? Individual success is celebrated. Language is low-context in nature, direct, with little concern for its impact on others ${ }^{[4,5,10]}$.

This cultural dimension has been found to critically impact communication and safety ${ }^{[5,6,7\}}$. Most profoundly is misinterpretation in communication, and the assumptions that come with the misinterpretation. For example, in addressing a problem, a simple and direct "You need to...." said by a person from an individualist perspective is simply relaying a need. Said to a collectivist, the statement can be easily misconstrued as rude, disrespectful or shaming. In addressing the same problem, a person from a collectivist background may ask, "What can we do..." in relaying the same message of need with the goal of maintaining harmony and respect of the working relationship. The question can be misconstrued by the individualist co-worker as a sign of incompetence or avoidance of truth.

\section{Implications in Nursing}

The worldview of "self" in the contexts of collectivism and individualism affect nursing clinically, in provider-patient and provider-provider relationships, and in education, in educator-student and educatoreducator relationships. In the provider-patient relationship, for example, it is known that many cultures make decisions collectively, usually as a family unit. Group decision-making can be complex and timeconsuming, and frustrates a provider from the individualist perspective to whom individual rights and autonomy is key to decision making. This is a common phenomenon observed by collectivists where providers have made comments along the lines of "You have the right to make your own decision...." Attempts of good intentions to communicate rights can back fire, as the directness in language is perceived as disrespectful and blame oriented which causes shame. Such misunderstandings have safety implications. Patients are known to sign out against medical advice, or in perceiving judgment, opts to withhold information critical to care. The opportunity for trust to develop is gone with possibly long-term consequences where healthcare is avoided with poor outcomes for the patients.

An example of this common cultural misunderstanding is demonstrated in the case of a young woman from the Middle East. She had just arrived with her engineer husband to the Bay Area. Being a devout Muslim, she was brought in by her husband for vaginal bleeding and abdominal pain. She needed a pelvic examination, which, by her culture, has to be performed by a female physician. There were only male physicians on duty that night at the Emergency Department (ED). As the team was trying to decide how best to care for her, a nurse went into the room and proceeded to lecture the patient and her husband that "They are in America now...." and told the patient that as a woman, she has the right to make her own decision on being examined by a male physician. Crying, the patient left the department with her husband. The offending nurse informed the team of what she had done, and commented it was "good riddance" that the patient and her husband had left. There were no concerns for patient safety: what if the patient had had an ectopic pregnancy? Why could not she be kept for observation for another 3 hours until the day female physician arrived? The reaction to the concerns was that healthcare providers should not "appease" a difficult patient, and that America simply could not cater to everyone’s cultural needs. 
The same dynamics apply to provider-provider relationships. It is especially poignant when the cultural dimension is complicated by how power is perceived and manifested (power distance between two entities) in the case of nurses from the collectivist tradition interacting with physicians or administrators from the individualist perspective. This is exemplified in a case where physicians refused to work with a newly arrived Nigerian nurse because the nurse was considered "incompetent" due to her indirect way of communication, and her accent. In the context of power distance, the physicians have not considered nurses as equal members of a team; nurses' suggestions, though medically appropriate, are often not given due consideration, as exemplified in the case of Emily Bromiley, in which the surgical team's failure to acknowledge nursing suggestions likely contributed to her death. ${ }^{[13]}$. This issue of power and perception of power remains a critical issue between physicians and other healthcare providers. As aptly conveyed by Dr. Atul Gawande, until physicians give up the perception of their autonomous individualism and truly accept the concept of teamwork, safety will continue to be an issue in healthcare ${ }^{[14]}$. Similarly, until these cultural dimensions are addressed, and that nurses and minority members are included as trainers of equal footing in training programs such as in TeamSTEPPS, real change will be difficult to achieve.

In education, it is a frequently heard complaint that students from Asian backgrounds lack initiative and are passive. Taught to learn from teachers, questioning a teacher is perceived as disrespectful and arrogant ${ }^{[15]}$. These students prefer one-on-one conferences where discussions are private leaving little room for shame or "losing face" for both the student and the teacher. This tradition to seek time with faculty has been interpreted as "needy" and frequently, these students are perceived as incompetent. The student would take a direct, confrontational approach by a faculty member as "losing face" and a failure. The sense of alienation can affect student productivity not out of the lack of ability but a misunderstanding in cultural expectations. The same goes for the faculty-student relationship: a teacher from a collectivist tradition may misinterpret a student's question to clarify an issue as disrespectful. A faculty member's indirect way of communicating in class can be perceived by a student as incompetence.

For faculty members from a collectivist tradition, adjusting to the expectations of academia can post a challenge that is difficult to overcome particularly the emphasis on individual success based on the tenure track process. At interviews, people are hired based on the answers to questions; globally, much misperception has occurred in interpreting the humble collectivist answer as incompetence, and the confident individualist answer as arrogant ${ }^{[4]}$. Language also frequently posts a challenge especially in the push to publish. These challenges urgently call for critical cultural awareness training, inclusivity, patience, and mentorship of faculty members if diversity is to be encouraged to develop patient-centered care that is culturally empathic ${ }^{[2]}$.

The combination of the reality of individualism and the perception of equality (as in a lack of power distance among members of a society) by the dominant culture in America creates an interesting psychological environment for minorities. The belief is that equality exists, and the expectation is such that success, as defined by the dominant culture, can be easily attainable by complete assimilation, the "You are in America" approach. Little consideration is given to the American-Indians, African-Americans, or other minorities who may not share the dominant culture's schema of thought. Indeed, what does the "You are in America" approach mean to these minority cultures? They have been alienated and oppressed by the very fact that the said equality of the society does not apply to them; their histories and realities are not acknowledged, and they are frequently blame for poor outcomes when care pathways are culturally insensitive ${ }^{[3,12]}$. Patient-centered care is much complicated than what white papers and policies call for; it entails a visit to what it really means to respect every culture as equal and not for the dominant culture to dictate what is right and wrong. As a society, patient-centered care calls for some soul-searching, in accepting that other cultures have a right to exist.

Cultural relativism can be a difficult place for most people. It has a sense of waywardness, a vulnerability that tells of a lack of answers. Does this mean doing away with standards or the many "truths" that we practice? Hardly. It requires a paradigm shift in how standards and "evidence-based" practices are viewed that the accepted practices are guidelines always with room for change and improvement ${ }^{[3]}$. A patient struggling with an "evidence-based" clinical pathway needs further investigation, as with the clinical outcome that is not achieved when the "evidence-based" pathway is followed, as in the classic example of medical providers failing to recognize signs and symptoms of acute myocardial infarct in women. 
Questions of "why" and "how" must follow instead of blaming the patient for non-compliance or for lack of truth telling. Indeed, acknowledging that medicine and nursing do not have all the answers is a start to cultural humility; it is in realizing that answers may be found elsewhere that we can start practicing culturally empathic and patient-centered care.

\section{Changing the Paradigm}

For more than two decades, the emphasis on "competency" focused on ethnic-based components, traditionally taught using the didactic method. Culture is narrowly defined in this approach in which lectures are based on texts, such as Cultural Sensitivity, a Pocket Guide for Health Care Professionals from the Joint Commission ${ }^{[16]}$, with chapters on specific ethnic cultures. Frequently, this cultural learning is one portion of a course in a tight curriculum, completed because of its "required" circumstance. While good in providing information, this methodology induces the mental models of stereotypes. Annual healthcare provider cultural competency is frequently measured based on this limited information where a learner is given a multiple choice test on dietary needs, religious practices, and specific behaviors associated with ethnicity. These trainings are almost always patient focused without consideration on how culture impacts patient-provider, and intra and inter-professional interactions. There is no critical processing and reflection on the definition and meaning of culture: what does culture entail; what is its impact on daily lives; how does it affect professional relationships; how does it influence health and healthcare?

The dominance of the majority may be a significant contributory factor to the problem of "cultural competency" as described. In nursing, the dominant culture comprises approximately $75 \%$ Whites, $69 \%$ of which are white women ${ }^{[2]}$. This phenomenon has contributed to a tradition within nursing that is parallel to that of ethnocentrism: "this is the way" and anyone interested in joining this "club" or the "in-group" must be willing to adopt, and adapt to, the dominant culture. Reflecting human development, the majority culture would most likely react to things new by becoming more protective of what is considered "ours". A quick browse of a newspaper confirms the reality of this cultural tension worldwide.

Following the same premise that Western psychology is blind to its own dominant Eurocentric culture, Christopher, et al. ${ }^{[3]}$ call for cultural competency to be readdressed. This lack of awareness of its own cultural foundation limits its ability to see how Western psychology is restricted to judging other cultures instead of being able to truly help those in need. Their position addresses what the authors consider critical cultural awareness, and is applicable across all healthcare disciplines:

- Increasing multiculturalism obliges all clinicians to critically reexamine our understanding of culture

- Western psychology is culture-bound. What has been assumed as "universal" is mostly peculiar to the American culture. The argument that objectivity exists only in Western science and that other approaches are culture-bound and based on non-science conveys the subjectivity of the Western approach. Accepting this limitation allows for learning from other traditions.

- The thrust towards quantitative data is premature in many areas of research, as much work is still needed in understanding language and cultural nuances of which the qualitative approach is more suited.

- Programs addressing critical cultural awareness must replace obligatory cultural competence education; such training must begin in the U.S. to catch-up with countries that have made significant progress such as Canada.

- The ethical imperative of non-maleficence obligates clinicians to develop critical cultural awareness, and the time to do so is now.

With this acknowledgement of the need for change comes the obligation to ask: how do we promote critical cultural awareness? Experiential learning in the form of immersion programs have been found to be effective in instilling early awareness that culture encompasses various components, and these differences most likely create discomfort when first encountered. Given knowledge and critical reflection, a new encounter can be guided towards understanding and the development of cultural humility, a position where one appreciates that culture is relative in meaning, and rights and wrongs have to be processed and 
appreciated contextually. This guidance has been identified as critical to the development of cultural awareness and respect ${ }^{\left[{ }^{[8]}\right.}$. While immersion program works, this approach is expensive, limited to those able to fund trips abroad ${ }^{[17]}$.

One way to recreate the experience of living through a cross-cultural interaction is to introduce students to cross-cultural gaming, a form of low fidelity simulation. It is an approach that has been effectively used for at least three decades by other industries, in many cases where safety and lives matter on how cultural nuance is interpreted ${ }^{[8,18,19,20]}$. Cross-cultural gaming is relatively unknown in healthcare with few articles mainly from outside the U.S. ${ }^{[21,22,23,24]}$.

Based on what is known in the literature, gaming is best used as part of a larger cross-cultural training program that calls for students to be put into new cultures, learn about cultural dimensions, and to reflect on their personal experiences and the experiences of others. Carefully planned, this training can be done in 4 hours, preferably 8 hours. Though much shorter than an immersion program abroad, it is a larger investment of time compared to reviewing a few chapters on ethnic-based practices and behavior with a few multiple test questions at the end. An important part of the gaming process is the debriefing process when the students get the opportunity to discuss their experiences and implications of participating in the game. An expert must lead the debriefing process on cross-cultural interactions for the process to have optimal learning value ${ }^{[19,20]}$. Implications should include the historical and sociological experiences of minorities best described using the language of cultural dimensions. Other components of the cross-cultural awareness "toolkit" include selected readings, short video vignettes on the impact of culture, reflective journaling by participants, and an evaluative tool or process ${ }^{[20,25]}$. The goal is for participants to reflect on awareness of their own culture and the culture of others, and how to respect the differences among the many cultures that exist in their daily lives.

\section{Summary: Implications for Nursing Leadership}

Increasing multiculturalism in our society poses the challenge of how health care providers have to meet the expectations of providing patient-centered care. Incidences of cultural insensitivity have consequences in patient outcomes. The persistence of a lack of awareness for other cultures may come from years of inadequate cultural competency training. Learning ethnic-based components of culture have not contributed to creating cultural awareness as the education has not included critical reflection of cultural dimensions, the role culture plays in daily lives, and how culture affects cross-cultural interactions. A contributory factor to this persistence may stem from the dominance of one culture among healthcare providers that can pose a challenge to being able to "see" the needs of others.

As shown by training in other industries from aviation to finance, critical cultural awareness can be developed with the right educational approach supported by leaders with foresight and the ability to see outside the "norm". Exposure to new cultures by way of gaming, with the guidance to critically reflect on the meaning of cultural dimensions in cross-cultural interactions, can lead to an appreciation of cultural relativity, and ultimately, cultural humility.

Nursing and healthcare leaders can begin this journey towards critical cultural awareness by readdressing cultural "competency". They should be the first to undertake critical cultural awareness training, if not by immersion abroad, then by experiential gaming. It is a challenge for everyone to come forth with an open mind and not think they have learned everything there is about culture. It is in the hands of leaders who have critical cultural awareness that our professional culture can change to be inclusive. Nursing and healthcare leaders must be willing to put in the investment if true cultural inclusivity is to occur. Perhaps, with critical cultural awareness, there will be less misunderstandings and incivility at work places. Perhaps minority candidates will be more inclined to join the profession. When we change our understanding of culture, "patient-centered care", "teamwork", and "safety" may get a true ring to their applications in healthcare. 


\section{Acknowledgements}

I thank Dr. Marjorie Barter and Dr. Daniel Morgan for their input and assistance in the writing of this article. 


\section{References}

1. Hendricks t. Bay Area/report: 112 languages spoken in divers region. SFGate. 2005 March 14. Available from: http://www.sfgate.com/bayarea/article/BAY-AREA-Report-112-languages

2. Bleich MR, MacWilliams BR, Schmidt BJ. Advancing diversity through inclusive excellence in nursing education. J Prof Nurs. 2014 September; 0(0):1-6. http://dx.doi.org/10.1016/j.profnurs.2014.09.003

3. Christopher JC, Wendt DC, Marecek J, Goodman DM. Critical cultural awareness. Am Psychol. 2014 October; 69(7):645-655. http://dx.doi.org/10.1037/a(X)36851

4. Hofstede G, Hofstede GJ, Minkov M. Cultures and organizations: software of the mind. McGraw-Hill International; c2010. 561 p.

5. Helmreich RL, Ashleigh CM. Culture at work in aviation and medicine. Ashgate International; c1998. 301 p.

6. Herkenhoff LM. Professional culture, emotional intelligence and the emotional process model. Journal of Organizational Leadership and Business. 2010 Summer. Available http://www.tamut.edu/jolb/scholar/2010summer/2010herkenhoff.pdf

7. d'Agincourt-Canning LG, Kissoon N, Singal M, Pitfield AF. Culture, communication and safety: lessons from the airline industry. Indian J Pediatr. 2011 June; 78(6):703-708. http://dx.doi.org/10.1007/s12098-010-0311-y

8. Hofstede GJ, de Caluwé L, Peters V. Why simulation games work-in search of the active substance: a synthesis. Simul Gaming. 2010 October; 41(6):824-843.

9. Kirkman BL, Lowe KB, Gibson CB. A quarter century of Culture's Consequences: a review of empirical research incorporating Hofstede’s cultural values framework. J Int Bus Stud. 2006 August; 37;285-320.

10. Mansyur CL, Amick BC, Harist RB, Franzini L, Roberts RE. The cultural production of health inequalities: a cross- sectional, multilevel examination of 52 countries. In J Health Serv. 2009; 39(2):301-319. Available from: http://www.pubfacts.com/detail/19492627/The-cultural-production-of-health-inequalities:-a-cross-sectional-mult ilevel-examination-of-52-count

11. Triandis HC. The many dimensions of culture. Academy of Management Executives [Internet]. 2004; 18(1). Available from: http://home.sandiego.edu/ pavett/docs/msgl_503/dim_of_cult.pdf

12. Furlong M, Wight J. Promoting “critical awareness” and critiquing "cultural competence”: towards disrupting received professional knowledges [Internet]. Aust J Soc Workers. 2011. Available from: http://dx.doi.org/10.1080/0312407x.2010.537352

13. Bromiley M. Just a routine operation [Internet]. Available from: https://www.youtube.com/watch?v=JzlvgtPIof4

14. Ho ES. Characteristics of East Asian learners: what we learned from PISA. Educational Research Journal, 20024(2):321-348. Available from http://www.fed.cuhk.edu.hk/ hkpisa/output/files/Ho_2010_erj_v24n2_327348.pdf

15. Gawande A. How do we heal medicine? TEDTalk. 2012 March. Available from: http://www.ted.com/talks/atul_gawande_how_do_we_heal_medicine?language=en

16. Galanti G, Woods MS. Cultural sensitivity, a pocket guide for health care professionals. Oakbrook Terrace: Joint Commission Resources; c2012. 50 p.

17. Kulbok PA, Mitchell EM, Glick DF, Greiner D. International experiences in nursing education: a review of the litereature. Int J Nurs Educ Scholarsh. 2012; 9(1). Available from: http://dx.doi.org/10.1515/1548-923X.2365

18. Hurn BJ. Simulation training methods to develop cultural awareness. Industrial and Commercial Training. 2011; 43(4):199-205. Available from: http://dx.doi.org/10.1108/00197851111137816

19. Lewis MM. The drama of international business. J of European Industrial Training. 2005 March; 29(7):593-398. Available from: http://dx.doi.org/10.1106/0309590510621072

20. Mills V, Smith R. short- and long-term effects of participation in a cross-cultural simulation game on intercultural awareness [Internet]. South Australia: Australian Government Department of Defence, Defence, Science and Technology Organisation; c2004. 63 p. Available from: http://dspace.dsto.defence.gov.au/dspace/handle/1947/3927

21. Graham I, Richardson E. Experiential gaming to facilitate cultural awareness: its implication for developing emotional caring in nursing. Learning in Health and Social Care. 2008; 7(1):37-45.

22. Koskinen L, Abdelhamid P. The simulation method for learning cultural awareness in nursing. Diversity in Health and Social Care. 2008; 5:55-63.

23. Kratzke C, Bertolo M. Enhancing students’ cultural competence using cross-cultural experiential learning. J Cult Divers. 2013; 20(3):107-113.

24. Peddle M. Simulation gaming in nurse education; entertainment or learning? Nurse Educ Today. 2011; 31:647649. Available from: http://dx.doi.org/10.1016/j.nedt.2010.12.009.

25. Ong-Flaherty C. A gap analysis of nursing systems and practices in Malaysia: culturally appropriate interventions to advance nursing [DNP project]. [San Francisco (CA)]; 2012. 117 p. 